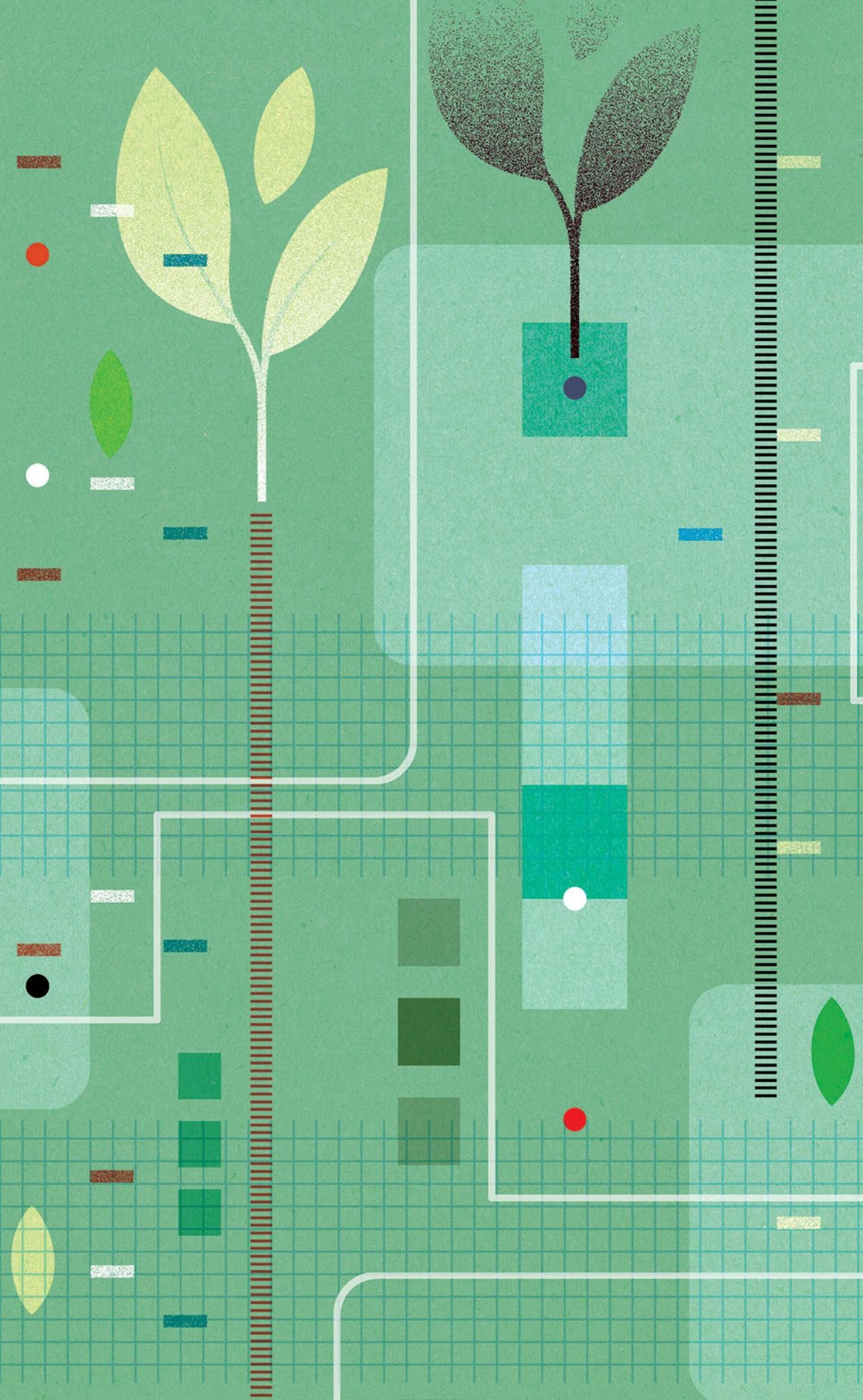




\title{
Desafios para uma agricultura sustentável: abordagem baseada em nos biomas brasileiros
}

\author{
Challenges for a sustainable agriculture: \\ an approach based on the Brazilion biomes
}

Antônio Márcio Buainain*
Arilson Favareto**
Junior Ruiz Garcia
Pedro Abel Vieira Junior

Resumo

A reflexão sobre os desafios para uma agricultura sustentável apresentada neste artigo toma como base os biomas, e não os recortes político-administrativos de municípios, unidades da federação e regiões, que não expressam adequadamente a oferta ambiental, que é a base de qualquer sistema agrícola. A abordagem adotada enfatiza as interdependências entre as dimensões econômica, social e ambiental, e as visões apresentadas foram colhidas em reuniões de trabalho realizadas nos 5 biomas, com a participação de pesquisadores, produtores e trabalhadores rurais, organizações não governamentais, formuladores e executores de políticas públicas e empresários direta e indiretamente envolvidos e preocupados com o desenvolvimento sustentável da agricultura brasileira.

Palavras-chave: Biomas brasileiros; desenvolvimento sustentável; agricultura brasileira.

\begin{abstract}
The reflection on the challenges to sustainable agriculture presented in this article is based on biomes, rather than on the political-administrative units of the federation and their regions. It is preferable because municipality units do not adequately express the environmental supply, the basis of any agricultural system. The approach adopted makes emphasis on the interdependencies between the economic, social and environmental dimensions. The views presented were collected at work meetings held in the 5 biomes, with the participation of researchers, producers and rural workers, non-governmental organizations, policy makers, bureaucrats and entrepreneurs directly and indirectly involved and concerned with the sustainable development of Brazilian agriculture.
\end{abstract}

Keywords: Brazilian biomes, sustainable development, Brazilian agriculture.

\footnotetext{
* Professor da Universidade de Campinas. E-mail: buainain@gmail.com

** Professor da Universidade Federal do ABC. E-mail: arilson.favareto@ufabc.edu.br

*** Professor da Universidade Federal do Paraná. E-mail: jrgarcia1989@gmail.com

**** Pesquisador da Embrapa. E-mail: pedroabelvieira@gmail.com
} 


\section{INTRODUÇÃO}

As recentes previsões da Organização das Nações Unidas para a Agricultura e Alimentação (FAO) sobre o crescimento da demanda mundial por alimentos (FAOSTAT, 2018; OCDC-FAO, 2017) não deixam dúvidas sobre o papel do Brasil: aumentar a produção de alimentos, fibras e energia e prover serviços ambientais, como "produzir" água e sequestrar carbono. Atender estas expectativas representa um enorme desafio para a agricultura e sociedade brasileira. Não é uma tarefa trivial, mas não há dúvidas que o Brasil tem potencial.

Na dimensão ambiental, a agricultura brasileira está iniciando a transição para sistemas mais sustentáveis (ROMEIRO, 2014). Este processo deve se acentuar tanto em função dos compromissos assumidos junto à comunidade internacional como das crescentes pressões da sociedade em favor de modelos de desenvolvimento mais sustentáveis. A difusão de programas "verdes", como a Agricultura de Baixo Carbono (MAPA, 2018a), além das produções agroecológica e orgânica (BRASIL, 2013) que, em 2016, já contabilizavam um milhão de hectares distribuídos em cerca de 15 mil estabelecimentos agropecuários, produzindo café, mel, hortaliças, açúcar, entre outros (IBGE, 2018a), confirmam o potencial deste eixo que até pouco era considerado como nicho.

Apesar dos esforços, o desmatamento e a degradação ainda persistem em todos os biomas (IBAMA, 2018; INPE, 2018; MAPBIOMAS, 2018; SOSMA, 2018a), e em um ritmo e dimensão incompatível com os compromissos internacionais assumidos pelo Brasil. $O$ desmatamento tem impacto direto na oferta hídrica (ANA, 2016, 2017), com a própria sustentabilidade da agricultura - dependente do regime de chuvas. Outros problemas antigos reemergem, como o uso de agroquímicos e a contaminação do solo, ar e água (Carneiro et al., 2015; IBGE, 2018) e a compactação do solo, além de novos desafios, como o uso da água e as ameaças sanitárias. Sem contar o agravamento dos ciclos de seca no Nordeste e as recentes crises hídricas nas regiões Sudeste e Centro Oeste, indicando que o potencial da irrigação na agricultura pode estar comprometido.

No campo econômico, o déficit logístico impõe perdas relevantes (PÉRA, 2018) e pode comprometer a competitividade de muitos segmentos da agricultura. Ademais, os ganhos de produtividade que contribuíram para a expansão dos últimos 20 anos têm perdido força (GASQUES; BACCHI; BASTOS, 2018; USDA, 2018), e em muitas áreas e cultivos a produtividade da terra tem oscilado e até decrescido no período mais recente (IBGE, 2018a). Inclui-se o front externo, com a importância da China (MAPA, 2018), embora a capacidade de oferta tenha crescido (IBGE, 2018a), estoques estejam recompostos e os preços ajustados para baixo (FAOSTAT, 2018), alinhando-se aos novos parâmetros dos mercados.

Cabe destacar ainda que o meio rural não acompanhou o desempenho da agricultura, com a persistência de problemas sociais graves (ALVES; ROCHA, 2010), sintetizados na pobreza rural e nas diferenças entre os indicadores de desenvolvimento 
humano da população rural e urbana (ATLAS BRASIL, 2018). Ademais, a despeito de impactos positivos sobre a economia local em muitas áreas, a dinâmica da agricultura moderna, produzida sob as condições da elevada concentração da propriedade da terra que caracteriza o Brasil, contribuiu para acentuar algumas tensões sociais, notadamente aquelas relacionadas à redução da absorção de mão de obra (GARCIA, 2014), à concentração produtiva mesmo em segmentos nos quais os agricultores familiares sempre foram numerosos e competitivos, e à dificuldade de impulsionar a diversificação inter setorial em muitos territórios altamente especializados na produção e exportação de grãos. Uma das evidências é que o crescimento da produtividade tem se concentrado em uma pequena proporção dos agricultores (ALVES; SOUZA; ROCHA, 2012).

Do ponto de vista de planejamento estratégico, é necessário superar a visão setorial das políticas públicas e a própria visão da sociedade sobre o agro em geral. A agricultura e o agricultor estão cada vez mais ligados ao mundo urbano, apesar da produção física estar no meio rural. Exceto pelo clima e oferta ambiental, a dinâmica da agricultura é cada vez mais determinada pela indústria e por serviços ofertados e disponíveis nas cidades, reforçando as crescentes interdependências entre o rural e o urbano, que precisam, portanto, serem analisados a partir de suas influências recíprocas.

A despeito desta constatação, a reflexão apresentada neste trabalho toma como base os biomas, e não o recorte político de municípios, unidades da federação e regiões, que não expressa adequadamente a oferta ambiental, que é a base de qualquer sistema agrícola. O bioma é um espaço geográfico cujas características são definidas com certo grau de homogeneidade pela oferta ambiental (IBGE, 2004), portanto, uma unidade mais adequada para análise do potencial de desenvolvimento da agricultura. Daí o objetivo deste artigo: discutir os desafios da agricultura em cada um dos seis biomas brasileiros (Amazônia, Cerrado, Caatinga, Mata Atlântica, Pantanal e Pampa).

Para isso o artigo está organizado em três seções, além da introdução e conclusões. A primeira é dedicada aos aspectos metodológicos. A segunda apresenta uma breve caracterização dos biomas e da agricultura brasileira. Na última são apresentados os resultados e a discussão.

\section{ASPECTOS METODOLÓGICOS}

Historicamente a produção agrícola é objeto de preocupação das sociedades, sugerindo que a atividade deve ser analisada a partir das suas especificidades frente outros setores produtivos. Esse tema ganhou relevância nos anos 80 e 90 no âmbito dos debates sobre a reprodução das formas familiares de produção em países de economia capitalista e sobre progresso tecnológico na agricultura (Mann e Dickinson, 1987). A questão central desse debate é compreender a importância da natureza como um fator explicativo do desenvolvimento da agricultura em ambientes, como 
por exemplo, a expansão das grandes lavouras de grãos nos cerrados brasileiros cuja área cultivada vem ampliando desde os anos 80, ou com o movimento da fronteira agropecuária nas bordas da Amazônia, bioma de enorme importância no contexto das mudanças climáticas globais. As relações sociais de produção, o desenvolvimento tecnológico, as políticas públicas e os impactos ambientais na agricultura de alguma maneira são influenciados pelo fator natureza. Ou seja, a natureza impõe alguma especificidade a essa atividade e o controle dessas especificidades, a despeito de progressos enormes nas últimas décadas, é caro, parece estar longe de ser alcançado, e para muitos nunca poderá ser completo. Inversamente, os impactos da agricultura no ambiente têm sido abordados desde a perspectiva dos efeitos das práticas agrícolas convencionais sobre os recursos naturais (vegetação, recursos hídricos, gases do efeito estufa, solo e etc.) bem como sobre a saúde do trabalhador e dos consumidores dos produtos agrícolas. Ou seja, a natureza desempenha um papel ativo no processo de produção agrícola e, deste modo, não pode ser desconsiderada ou colocada em segundo plano, tal como se verifica no pensamento das principais correntes que se preocuparam apenas com o progresso técnico. $E$ sob o ângulo oposto, a atividade agrícola acarreta efeitos ambientais inequívocos. Não se trata de uma defesa 'do meio ambiente', simplesmente, mas, essencialmente, de recolocar o debate sobre o desenvolvimento da agricultura a partir de uma perspectiva da sua especificidade frente a outros processos sociais e econômicos e de suas relações de causação recíproca com os sistemas naturais. Finalmente, tampouco se pode dissociar o desenvolvimento da agricultura das consequências e dos condicionantes sociais da atividade agrícola sobre o desenvolvimento do espaço rural.

O Brasil tem premência, e pouca tradição, em desenvolver projetos de interesse nacional, com foco em sistemas complexos que exijam atuação integradora e eficácia gerencial. Isso porque o desenvolvimento não pode ser mais visto como apenas sinônimo de crescimento do PIB. É preciso avançar na direção de uma perspectiva multidimensional, que inclua minimamente outros aspectos da dimensão econômica, juntamente com elementos e critérios de eficiência relativos às dimensões social e ambiental. Analisar a agricultura e suas perspectivas futuras nestes termos, analisar a agricultura torna-se não só uma mera questão de estilo ou de escolha. Não se trata apenas afirmar que ganhos econômicos podem trazer prejuízos sociais e ambientais. Mas sim que não é possível adotar estratégias de desenvolvimento que não equacionem a desigualdade e a pobreza, ao mesmo tempo em que se toma o respeito aos limites dos ecossistemas como algo imperativo.

Neste contexto, uma abordagem baseada nos biomas brasileiros representa a possibilidade maior para a adoção de uma visão abrangente para tratar a agricultura. Os estudos sobre a agricultura têm sido organizados com base no recorte político, como municípios, unidades da federação e regiões, o que não expressa adequadamente a oferta ambiental, elemento central para qualquer sistema agrícola. O bioma' é um espaço geográfico cujas características são definidas, com certo grau 
de homogeneidade em termos da flora e fauna, elementos da oferta ambiental (IBGE, 2018b). Apesar disso, os biomas são heterogêneos em termos ambientais, econômicos e sociais e de infraestrutura.

O Brasil tem em seu território seis biomas: Amazônia, Cerrado, Caatinga, Mata Atlântica, Pantanal e Pampa (Mapa 1). Cada um deles com dinâmica interna própria, mas também uma relação de interdependência com os demais. Na perspectiva dos sistemas hídricos, por exemplo, o Cerrado é um bioma-chave para os demais uma vez que seu território contém as cabeceiras de importantes bacias hidrográficas, tais como São Francisco, Tocantins e Araguaia; o Bioma Amazônia contribui decisivamente para o regime de chuvas no Bioma Mata Atlântica. Na próxima seção é apresentada uma breve caracterização dos biomas.

\section{Mapa 1 - Biomas Continentais do Brasil}
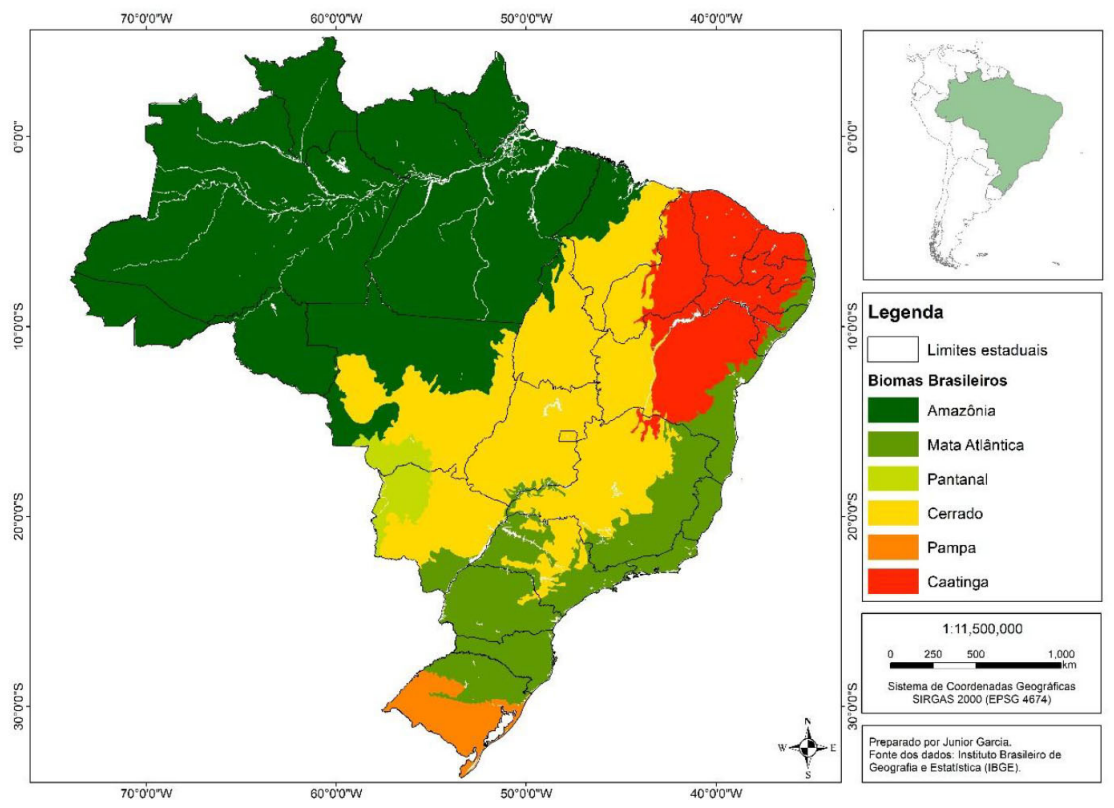

Fonte: preparado com base em (IBGE, 2018c).

Este artigo antecipa alguns dos resultados do esforço de reflexão realizado pelo BID e Embrapa no contexto do planejamento estratégico do BID. Nesta iniciativa se utilizou a metodologia de reuniões de trabalho semiestruturadas, envolvendo pesquisadores, profissionais inseridos em atividades vinculadas à agricultura e desenvolvimento rural, organizações da sociedade civil, produtores rurais, líderes sindicais e patronais e 
agentes públicos, para discutir o desenvolvimento sustentável da agricultura em cada um dos 6 biomas brasileiros. As reuniões contaram com a participação média de 50 pessoas, que se dividiram em grupos de trabalho de até 8 pessoas, para refletir sobre alguns eixos temáticos, buscando responder perguntas especialmente formuladas para promover a troca de informação, debates e a busca por conclusões ou pelo mapeamento de convergências e controvérsias.

Ao todo foram realizadas seis reuniões, uma em cada bioma. As atividades iniciavam com uma apresentação sobre aspectos econômicos, sociais e ambientais e os desafios da agricultura no bioma em questão por um pesquisador da Embrapa. Em seguida, os pesquisadores responsáveis pela organização das oficinas apresentaram as orientações para os trabalhos, destacando as particularidades das dimensões econômica, social e ambiental e a necessidade de abordagem integrada dos temas. Na sequência, os grupos de trabalho eram convidados a refletir sobre questões específicas dedicadas a identificação dos principais desafios econômicos, sociais e ambientais para uma agricultura sustentável ${ }^{2}$. Ao final de cada atividade os grupos apresentaram seus resultados a todos os participantes. Na parte final os grupos foram instados a refletir sobre as ações necessárias à elaboração de políticas públicas dedicadas a encaminhar soluções práticas e efetivas para o respectivo bioma. As ações também foram discutidas em plenária. O trabalho de cada grupo foi consolidado por uma equipe. E, o conjunto de considerações e propostas, formulados nas oficinas para cada bioma, deu origem a um relatório geral apontando as tendências e desafios para o desenvolvimento sustentável da agricultura brasileira.

\section{OS BIOMAS BRASILEIROS E A AGROPECUÁRIA}

O Bioma Amazônia ocupa 6,9 milhões de $\mathrm{Km}^{2}$, abrange 9 países (IBGE, 2018b); no Brasil a área é de 4,2 milhões $\mathrm{km}^{2}$, contando com 20 milhões de pessoas; Índice Firjan de Desenvolvimento Municipal de 0,568 (regular desenvolvimento) em 2016 (Tabela 1); Produto Interno Bruto (PIB) de R\$ 370 bilhões e Valor Adicionado Bruto (VAB) de $R \$ 327,1$ bilhões em 2015 (Tabela 2). O bioma abriga a maior floresta tropical do mundo, a Floresta Amazônica, responsável por importantes serviços ecossistêmicos (MEA, 2003), provedora de diversidade genética, captura e armazenamento de carbono, enorme influência no ciclo hidrológico, entre outros. Apesar disso, no bioma está localizada importante produção agropecuária, com destaque para soja, milho e pecuária bovina (Tabela 3e 5). De menor valor comercial, mas fundamental para os produtores familiares, as atividades extrativas e a pesca merecem destaque. $\mathrm{O}$ resultado da ocupação agropecuária mostra que o desmatamento acumulado alcançou 18,5\% da área do bioma no Brasil (Tabela 1). Em razão de sua importância ambiental, estima-se que $34 \%$ do território esteja protegido em unidades de conservação (Tabela 1), embora não seja um percentual que garanta sua integridade e sustentabilidade. 


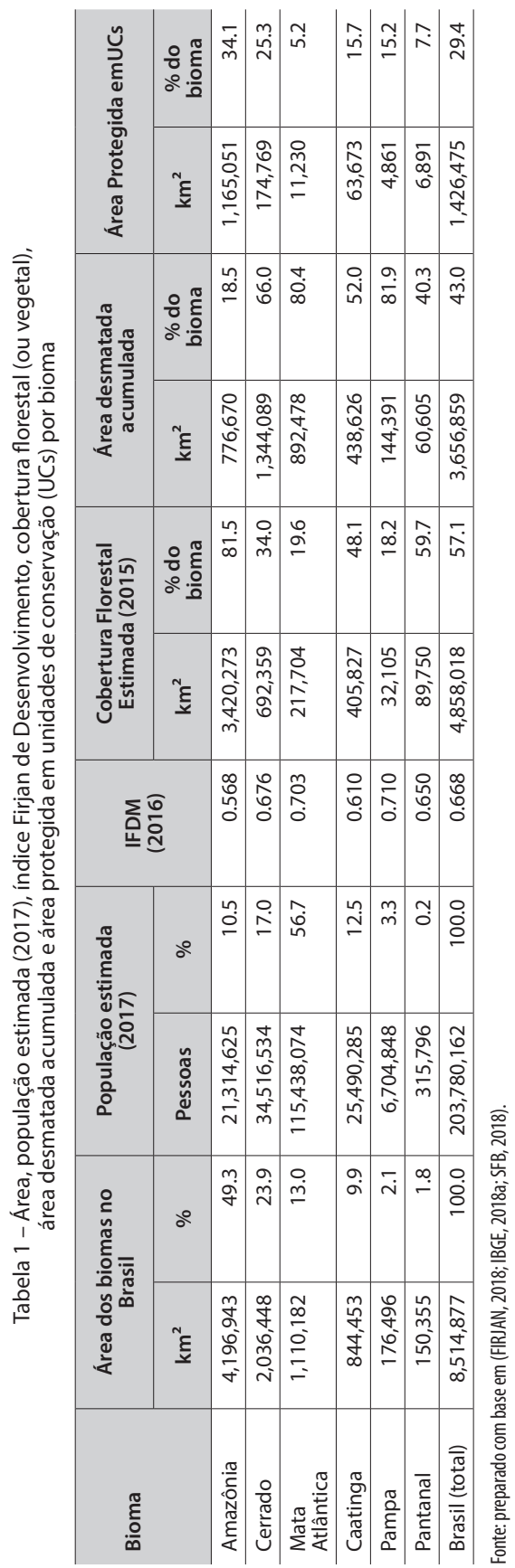


Tabela 2 - População total e participação $\%$ urbana e rural por bioma: 2010

\begin{tabular}{l|r|c|c}
\hline Bioma & Total pessoas & Urbana (\%) & Rural (\%) \\
\hline Amazônia & $19,163,412$ & 71.3 & 28.7 \\
\hline Caatinga & $23,923,390$ & 64.8 & 35.2 \\
\hline Cerrado & $31,335,084$ & 86.0 & 14.0 \\
\hline $\begin{array}{l}\text { Mata } \\
\text { Atlântica }\end{array}$ & $109,666,431$ & 90.0 & 10.0 \\
\hline Pampa & $6,364,488$ & 91.5 & 8.5 \\
\hline Pantanal & 300,364 & 79.7 & 20.3 \\
\hline Brasil & $190,753,169$ & 84.4 & 15.6 \\
\hline
\end{tabular}

Fonte: preparado com base em (IBGE, 2018a).

Tabela 3 - Produto Interno Bruto (PIB) e Valor Adicionado Bruto (VAB) por bioma (bilhões R\$): 2015

\begin{tabular}{l|r|r|c|c|c}
\hline \multirow{2}{*}{ Biomas } & \multirow{2}{*}{ PIB } & \multicolumn{4}{|c}{ VAB - Valor Adicionado Bruto } \\
\cline { 3 - 6 } & & Total & Agropecuário & Industrial & Serviços \\
\hline Amazônia & 369.4 & 327.1 & 35.8 & 80.6 & 130.5 \\
\hline Caatinga & 297.3 & 268.3 & 18.5 & 45.4 & 119.6 \\
\hline Cerrado & $1,025.3$ & 906.6 & 75.3 & 174.8 & 454.6 \\
\hline $\begin{array}{l}\text { Mata } \\
\text { Atlântica }\end{array}$ & $4,015.9$ & $3,403.1$ & 115.2 & 810.9 & $1,996.9$ \\
\hline Pampa & 218.9 & 189.9 & 12.9 & 39.4 & 109.1 \\
\hline Pantanal & 6.1 & 5.6 & 1.0 & 0.7 & 2.3 \\
\hline Brasil & $5,995.8$ & $5,155.6$ & 259.0 & $1,160.8$ & $2,850.3$ \\
\hline
\end{tabular}

Fonte: preparado com base em (IBGE, 2018a).

Tabela 4 - Principais grupos de utilização das terras por bioma: 2017 (hectares)

\begin{tabular}{l|c|c|c|c|c}
\hline Biomas & $\begin{array}{c}\text { Lavoura } \\
\text { permanente }\end{array}$ & $\begin{array}{c}\text { Lavoura } \\
\text { temporária }\end{array}$ & Pastagens & $\begin{array}{c}\text { Floresta } \\
\text { Natural }\end{array}$ & Outros usos $^{\mathbf{2}}$ \\
\hline Amazônia & $1,146,029$ & $5,033,790$ & $39,370,197$ & $33,618,873$ & $1,783,128$ \\
\hline Caatinga & 952,037 & $3,181,603$ & $14,035,413$ & $9,649,786$ & $6,256,466$ \\
\hline Cerrado & $2,031,076$ & $23,773,566$ & $58,417,935$ & $32,123,935$ & $6,875,485$ \\
\hline $\begin{array}{l}\text { Mata } \\
\text { Atlântica }\end{array}$ & $3,672,241$ & $19,362,040$ & $31,784,807$ & $13,770,842$ & $5,532,742$ \\
\hline Pampa & 82,059 & $3,727,024$ & $7,474,406$ & $1,141,716$ & 196,464 \\
\hline Pantanal & 15,341 & 51,405 & $6,930,393$ & $2,337,862$ & 325,290 \\
\hline Brasil & $7,907,604$ & $55,237,349$ & $158,337,913$ & $92,793,381$ & $21,519,326$ \\
\hline
\end{tabular}

Fonte: preparado com base em (IBGE, 2018a).

${ }^{1}$ inclui as áreas de preservação permanente ou reserva legal. ${ }^{2}$ corresponde ao uso com florestas plantadas e sistemas agroflorestais. 
Tabela 5 - Síntese das Principais atividades agropecuárias por bioma: 2017

\begin{tabular}{|c|c|c|c|c|}
\hline Bioma & Atividade & Área (ha.) & $\begin{array}{c}\text { Valor da produção } \\
\text { (R\$) }\end{array}$ & Rebanho (cabeças) \\
\hline \multirow[t]{6}{*}{ Amazônia } & Soja & $3,608,910$ & $10,442,209$ & \\
\hline & Mandioca & 541,983 & $4,221,577$ & \\
\hline & Milho & $1,591,106$ & $2,945,512$ & \\
\hline & Aves & & & 55,035 \\
\hline & Bovinos & $37,459,054$ & $4,763,774,438$ & $47,115,977$ \\
\hline & Suínos & & 402,606 & $2,308,859$ \\
\hline \multirow[t]{6}{*}{ Caatinga } & Banana & 98,215 & $1,436,713$ & \\
\hline & Mandioca & 235,134 & 780,68 & \\
\hline & Feijão & $1,188,915$ & 704,159 & \\
\hline & Aves & & & 76,976 \\
\hline & Bovinos & $11,725,962$ & $301,720,149$ & $9,735,888$ \\
\hline & Suínos & & 466,556 & $2,751,302$ \\
\hline \multirow[t]{6}{*}{ Cerrado } & Soja & $16,549,002$ & $48,997,547$ & \\
\hline & Cana de açúcar & $4,560,138$ & $24,162,447$ & \\
\hline & Milho & $7,392,766$ & $17,689,978$ & \\
\hline & Aves & & & 344,303 \\
\hline & Bovinos & $56,561,284$ & $8,104,923,681$ & $58,464,406$ \\
\hline & Suínos & & $2,752,493$ & $8,814,365$ \\
\hline \multirow[t]{6}{*}{ Mata Atlântica } & Soja & $10,700,083$ & $38,459,603$ & \\
\hline & Cana de açúcar & $5,390,117$ & $25,915,295$ & \\
\hline & Milho & $5,281,165$ & $16,002,712$ & \\
\hline & Aves & & & 969,446 \\
\hline & Bovinos & $30,107,242$ & $4,199,963,379$ & $44,333,252$ \\
\hline & Suínos & & $7,842,829$ & $24,885,826$ \\
\hline \multirow[t]{6}{*}{ Pampa } & Soja & $2,325,512$ & $6,616,454$ & \\
\hline & Arroz & $1,022,948$ & $5,663,113$ & \\
\hline & Fumo & 70,078 & $1,208,222$ & \\
\hline & Aves & & & 6,473 \\
\hline & Bovinos & $7,277,828$ & $928,011,836$ & $7,794,264$ \\
\hline & Suínos & & 44,03 & 354,065 \\
\hline \multirow[t]{6}{*}{ Pantanal } & Soja & 39,627 & 135,144 & \\
\hline & Milho & 16,199 & 42,272 & \\
\hline & Cana de açúcar & 8,632 & 35,428 & \\
\hline & Aves & & & 1,031 \\
\hline & Bovinos & $6,535,999$ & $564,697,304$ & $4,410,490$ \\
\hline & Suínos & & 6,274 & 52,709 \\
\hline
\end{tabular}

Fonte: preparado com base em (IBGE, 2018a). 
O Bioma Cerrado ocupa 2 milhões de $\mathrm{Km}^{2}$, população de 34,5 milhões de pessoas e Índice Firjan de Desenvolvimento Municipal de 0,676 (moderado desenvolvimento) em 2016 (Tabela 1); Produto Interno Bruto (PIB) de R\$ 1 trilhão e Valor Adicionado Bruto (VAB) de R\$ 906 bilhões em 2015 (Tabela 2). O bioma abriga nascentes das três maiores bacias hidrográficas da América do Sul - Amazônica/Tocantins, São Francisco e do Prata - (ANA, 2018), além de significativa biodiversidade (IBGE, 2004). Apesar disso, no bioma está localizada a principal área de produção agropecuária do Brasil, com destaque para o Complexo soja-milho, avanço do Complexo Sucroalcooleiro e de Carnes (Tabela 3e 5). Desse modo, o bioma registra uma taxa de desmatamento acumulado de $66 \%$ da sua área (Tabela 1), sem indicativos de redução (IBAMA, 2018; MAPBIOMAS, 2018). Em razão de sua importância ambiental, estima-se que $25 \%$ do território esteja protegido em unidades de conservação (Tabela 1), o que, também neste caso, não significa garantia de integridade e sustentabilidade. É a região com menor presença relativa da agricultura familiar.

O Bioma Caatinga ocupa 845 mil $\mathrm{Km}^{2}$, único bioma exclusivamente brasileiro e com características próprias, abrigando 25,5 milhões de pessoas (Tabela 1) - maior população em região semiárida do mundo -, tendo também a maior parcela da população rural dos biomas brasileiros; Índice Firjan de Desenvolvimento Municipal de 0,610 (moderado desenvolvimento) em 2016 (Tabela 1); Produto Interno Bruto (PIB) de R\$ 297,3 bilhões e Valor Adicionado Bruto (VAB) de R\$ 268,3 bilhões em 2015 (Tabela 2). Apesar de ser uma região semiárida, com significativos processos de desertificação (CASIMIRO FILHO; IVONEIDE; RODRIGUES, 2016), o bioma abriga importante produção agropecuária comercial, com destaque para o cultivo de frutas em perímetros irrigados(Buainain \& Garcia, 2015), pecuária bovina e grãos (Tabela 3e 5). Entre agricultores familiares predominam cultivos como mandioca, milho e feijão e criação de pequenos animais, destacadamente caprinos e ovinos. $O$ resultado da histórica ocupação e sobre-utilização dos recursos naturais mostra que o desmatamento acumulado alcançou 52\% do bioma (Tabela 1), contribuindo para a desertificação (MMA, 2018) e ampliando as restrições à produção e geração de emprego e renda. Apenas 15,7\% do bioma está protegido em unidades de conservação (Tabela 1).

O Bioma Mata Atlântica ocupa 1,1 milhão de $\mathrm{Km}^{2}$; conta com população de 115,5 milhões de pessoas; Índice Firjan de Desenvolvimento Municipal de 0,703 (moderado desenvolvimento) em 2016 (Tabela 1); Produto Interno Bruto (PIB) de R\$ 4 trilhões e Valor Adicionado Bruto (VAB) de R\$ 3,4 trilhões em 2015 (Tabela 2). A Mata Atlântica é o mais heterogêneo e modificado bioma do Brasil; além de abrigar importante parcela da produção agropecuária, é responsável pela quase totalidade da produção industrial e de serviços mais complexos; apresenta um conjunto de formações vegetais com grande diversidade, estendendo-se dos trópicos até as áreas de clima temperado. Apesar do grau de degradação - com área desmatada acumulada superior a $80 \%$ (Tabela 1), o Atlas da Mata Atlântica indica que os remanescentes florestais representam apenas $10 \%$ da área original do bioma (SOSMA, 2018a) -, abriga espécies endêmicas 
(SOSMA, 2018b). A produção agropecuária está concentrada no Complexo SojaMilho, Sucroalcooleiro e Carnes (Tabela 3e 5). Minoritária nestas cadeias, a agricultura familiar local tem importância significativa na produção de café, lácteos, frutas e hortaliças. Apesar de sua importância ambiental e de seu elevado grau de degradação, estima-se que apenas 5,2\% do território esteja protegido em unidades de conservação (Tabela 1). O alto grau de urbanização neste bioma coloca a conservação dos recursos naturais como tema crucial para as populações das cidades, várias delas sendo afetadas nos últimos anos por episódios de crise hídrica e risco de abastecimento.

O Bioma Pantanal ocupa apenas $250 \mathrm{mil} \mathrm{Km}^{2}$; no Brasil a área é de $150 \mathrm{mil}$ $\mathrm{km}^{2}$ - uma das maiores planícies alagadas contínuas do mundo -, conta com uma população de 316 mil pessoas; Índice Firjan de Desenvolvimento Municipal de 0,650 (moderado desenvolvimento) em 2016 (Tabela 1); Produto Interno Bruto (PIB) de $\mathrm{R} \$$ 6,1 bilhões e Valor Adicionado Bruto (VAB) de R\$ 5,6 bilhões em 2015 (Tabela 2). O bioma é considerado pela UNESCO Patrimônio Natural Mundial e Reserva da Biosfera. Em função das suas características ambientais, a principal atividade agropecuária é a pecuária bovina extensiva (Tabela 3e 5). Mesmo assim, a área degradada acumulada alcança $40 \%$, e apenas $7,7 \%$ de sua área está protegida na forma de unidades de conservação (Tabela 1). O bioma sofre forte influência da dinâmica estabelecida no Bioma Cerrado.

Por fim, o Bioma Pampa, que na parcela brasileira ocupa 176,5 mil $\mathrm{Km}^{2}$ do estado do Rio Grande do Sul, com uma população de 6,7 milhões de pessoas; Índice Firjan de Desenvolvimento Municipal de 0,710 (moderado desenvolvimento) em 2016 (Tabela 1); Produto Interno Bruto (PIB) de R\$ 219 bilhões e Valor Adicionado Bruto (VAB) de R\$ 190 bilhões em 2015 (Tabela 2). O bioma é caracterizado pela presença de planícies com coxilhas recobertas por campos naturais - mais de 450 espécies de gramíneas e 150 leguminosas, plantas rasteiras e árvores e arbustos próximos aos corpos d'água (IBGE, 2004). Dessa maneira, no bioma está localizada importante produção agropecuária, com destaque para soja, arroz e pecuária bovina (Tabela 3 e 5). O resultado da ocupação agropecuária mostra que o desmatamento acumulado alcançou $82 \%$ da área do bioma no Brasil (Tabela 1), com alto grau de degradação. Estima-se que 15\% do território esteja protegido em unidades de conservação (Tabela 1).

A produção agropecuária realizada nos biomas brasileiros contribuiu com $5 \%$ do Produto Interno Bruto (PIB) em 2017 (IBGE, 2018a), e 22\% quando considerados os encadeamentos intersetoriais com a indústria, comércio e serviços (CEPEA, 2018). As exportações do setor alcançaram US\$ 96 bilhões, 45\% das exportações do país em 2017 (MAPA, 2018b). Esse desempenho garantiu ao país uma participação de 7\% no mercado agropecuário global, mas concentrada em cereais, carnes, oleaginosas, fibras e frutas (UN COMTRADE, 2018), com participação crescente dos complexos soja e carnes. Como visto, o Valor Adicionado Bruto (VAB) agropecuário e o PIB estão concentrados na Mata Atlântica e Cerrado (Tabela 2), mas o Bioma Amazônia abriga 40 
milhões de hectares em pastagens. Os dados do Censo Agropecuário 2017 revelaram que os estabelecimentos agropecuários envolvem quase 93 milhões de hectares em áreas de preservação permanente (APP), reserva legal ou florestas naturais, com destaque para os Biomas Amazônia e Cerrado (Tabela 3). Apesar disso, como já mencionado, o desmatamento persiste nestes biomas (INPE, 2018; MAPBIOMAS, 2018).

Essa breve contextualização dos biomas brasileiros permite agora introduzir considerações e hipóteses para o desenvolvimento de uma agricultura sustentável no Brasil

\section{RESULTADOS E DISCUSSÃO}

Nos quadros 1, 2 e 3 estão apontados os principais desafios para o desenvolvimento de uma agricultura sustentável nos biomas, tendo por base as considerações tecidas pelos participantes do conjunto de oficinas realizadas, organizados de acordo com a dimensão a que dizem respeito. Essa abordagem foi adotada para auxiliar na análise e no direcionamento das políticas e ações para o seu enfrentamento. A maioria dos desafios têm imbricações em todas as dimensões, uma vez que refletem uma abordagem orientada pela ideia de desenvolvimento sustentável. Do ponto de vista estratégico, o principal desafio está justamente em superar a visão e ação fragmentada que tem marcado a atuação dos setores públicos e privados. A abordagem predominante em grande medida parece operar como se a dimensão econômica não estivesse diretamente associada à social e ambiental; ou que os aspectos ambientais não tenham repercussão direta sobre temas econômicos e sociais. Para uma agricultura sustentável as dimensões devem ser tratadas como interdependentes e transversais.

A produção agropecuária se assenta e depende, de forma essencial, dos serviços ecossistêmicos (PALM et al., 2014; ZHANG et al., 2007), e a degradação ambiental compromete seriamente a sustentabilidade, em uma visão de longo prazo, do setor e sua competitividade. A ilusão de que é possível compensar e substituir a natureza por tecnologia vai se mostrando cada vez mais insustentável (CARNEIRO et al., 2015; ROMEIRO, 2014), seja pela elevação dos custos de produção, seja pelos impactos ambientais negativos, ou pelo distanciamento das demandas que aos poucos vão se tornando imperativas, por alimentos seguros (seguridade alimentar), proteção ambiental, inclusão social. 
Quadro 1 - Principais desafios por bioma e dimensão ambiental, segundo os participantes das oficinas ${ }^{1}$

\begin{tabular}{|c|c|c|c|c|c|c|}
\hline Desafios & Cerrado & Caatinga & Amazônia & $\begin{array}{c}\text { Mata } \\
\text { Atlântica }\end{array}$ & Pantanal & Pampa \\
\hline $\begin{array}{l}\text { Adoção de pagamento } \\
\text { por serviços ambientais }\end{array}$ & $\mathrm{x}$ & $\mathrm{x}$ & $x$ & $\mathrm{x}$ & $\mathrm{x}$ & $\mathrm{x}$ \\
\hline $\begin{array}{l}\text { Ampliar os investimentos } \\
\text { em fiscalização }\end{array}$ & $x$ & & & $\mathrm{x}$ & $\mathrm{x}$ & \\
\hline $\begin{array}{l}\text { Aproveitamento da } \\
\text { biodiversidade }\end{array}$ & $x$ & $\mathrm{x}$ & $x$ & $x$ & $x$ & \\
\hline Gestão hídrica & $x$ & $x$ & $x$ & $x$ & $\mathrm{x}$ & $x$ \\
\hline $\begin{array}{l}\text { Criação e gestão de } \\
\text { unidades de conservação } \\
\text { (UCs) }\end{array}$ & $x$ & $x$ & & $x$ & & $x$ \\
\hline $\begin{array}{l}\text { Criar fundos de apoio à } \\
\text { compensação ambiental }\end{array}$ & & & & $x$ & $x$ & \\
\hline $\begin{array}{l}\text { Gestão adequada dos } \\
\text { resíduos produtivos }\end{array}$ & $x$ & & & & & $x$ \\
\hline $\begin{array}{l}\text { Implementar programas } \\
\text { de educação ambiental }\end{array}$ & $\mathrm{x}$ & $\mathrm{x}$ & & $\mathrm{x}$ & & \\
\hline $\begin{array}{l}\text { Incentivar a certificação } \\
\text { ambiental }\end{array}$ & $x$ & $x$ & $x$ & $\mathrm{x}$ & $x$ & $\mathrm{x}$ \\
\hline $\begin{array}{l}\text { Incentivar a eficiência no } \\
\text { uso dos recursos naturais }\end{array}$ & $\mathrm{x}$ & $\mathrm{x}$ & & & & $\mathrm{x}$ \\
\hline $\begin{array}{l}\text { Promover a regularização } \\
\text { ambiental }\end{array}$ & & $\mathrm{x}$ & $x$ & $x$ & $x$ & \\
\hline $\begin{array}{l}\text { Recuperação das áreas } \\
\text { degradadas (em sentido } \\
\text { amplo) }\end{array}$ & $\mathrm{x}$ & $\mathrm{x}$ & $\mathrm{x}$ & $\mathrm{x}$ & $x$ & $\mathrm{x}$ \\
\hline Saneamento básico & & & $x$ & $x$ & $x$ & \\
\hline
\end{tabular}

${ }^{1}$ a criação de cada grupo temático foi realizada com base na dimensão predominante de cada ação/potencialidade. É evidente que cada ação/ potencialidade tem interface com as dimensões social e econômica além da ambiental. Cabe destacar que cada ação/potencialidade listada no grupo temático "Ambiental" tem por objetivo principal a recuperação da qualidade ambiental perdida em função do uso "inadequado" dos recursos naturais ou a preservação da qualidade ambiental do Bioma em questão, neste caso, do Cerrado.

Quadro 2 - Principais desafios por bioma e dimensão social, segundo os participantes das oficinas. ${ }^{1}$

\begin{tabular}{|c|c|c|c|c|c|c|}
\hline Desafios $^{2}$ & Cerrado & Caatinga & Amazônia & $\begin{array}{c}\text { Mata } \\
\text { Atlântica }\end{array}$ & Pantanal & Pampa \\
\hline $\begin{array}{l}\text { Assistência técnica e } \\
\text { extensão rural }\end{array}$ & $x$ & $x$ & $x$ & $x$ & $x$ & $x$ \\
\hline $\begin{array}{l}\text { Fortalecer as } \\
\text { organizações sociais } \\
\text { (cooperativas e } \\
\text { associações) }\end{array}$ & $x$ & $x$ & $x$ & $x$ & $x$ & $x$ \\
\hline $\begin{array}{l}\text { Melhoramento da } \\
\text { educação formal (ensino } \\
\text { fundamental, médio etc.) } \\
\text { do produtor }\end{array}$ & $x$ & $x$ & $x$ & $x$ & $x$ & $x$ \\
\hline $\begin{array}{l}\text { Melhorar a distribuição } \\
\text { de renda }\end{array}$ & $x$ & $\mathrm{x}$ & $x$ & $\mathrm{x}$ & $x$ & $x$ \\
\hline $\begin{array}{l}\text { Planejar a sucessão } \\
\text { familiar (permanência do } \\
\text { produtor) }\end{array}$ & $x$ & $x$ & & $x$ & $\mathrm{x}$ & $x$ \\
\hline $\begin{array}{l}\text { Promover a inclusão dos } \\
\text { pequenos produtores }\end{array}$ & $x$ & & & $x$ & $x$ & $x$ \\
\hline $\begin{array}{l}\text { Reconhecer a } \\
\text { importância dos saberes } \\
\text { locais (conhecimento } \\
\text { tradicional) e mapear as } \\
\text { comunidades tradicionais }\end{array}$ & $x$ & $x$ & $x$ & $x$ & $\mathrm{x}$ & $x$ \\
\hline Regularizaçãofundiária & $x$ & $x$ & $x$ & $x$ & $x$ & \\
\hline
\end{tabular}


Quadro 3 - Principais desafios por bioma e dimensão econômica, segundo os participantes das oficinas'

\begin{tabular}{|c|c|c|c|c|c|c|}
\hline Desafios $^{2}$ & Cerrado & Caatinga & Amazônia & $\begin{array}{c}\text { Mata } \\
\text { Atlântica }\end{array}$ & Pantanal & Pampa \\
\hline $\begin{array}{l}\text { Acessibilidade ao crédito } \\
\text { e financiamento }\end{array}$ & $x$ & $x$ & $x$ & $x$ & $x$ & $x$ \\
\hline $\begin{array}{l}\text { Adoção de sistemas } \\
\text { integrados de produção } \\
\text { (orgânica, agroecológica, } \\
\text { agroflorestais etc.) }\end{array}$ & $x$ & $x$ & $x$ & $x$ & $x$ & $x$ \\
\hline $\begin{array}{l}\text { Ampliação dos sistemas } \\
\text { irrigados }\end{array}$ & $x$ & $x$ & & & & \\
\hline $\begin{array}{l}\text { Avançar no planejamento } \\
\text { agropecuário (ZEE, planos } \\
\text { de bacias, inteligência } \\
\text { territorial etc.) }\end{array}$ & $x$ & $x$ & $x$ & $x$ & $x$ & $x$ \\
\hline $\begin{array}{l}\text { Certificação e indicação } \\
\text { geográfica }\end{array}$ & $x$ & $x$ & $x$ & $\mathrm{x}$ & $\mathrm{x}$ & $x$ \\
\hline $\begin{array}{l}\text { Definir práticas } \\
\text { regulamentadas de uso } \\
\text { da reserva legal }\end{array}$ & $x$ & & $x$ & & & $x$ \\
\hline $\begin{array}{l}\text { Difusão das inovações e } \\
\text { tecnologias }\end{array}$ & $x$ & $x$ & $x$ & $x$ & $x$ & $x$ \\
\hline $\begin{array}{l}\text { Diversificação e } \\
\text { agregação de valor a } \\
\text { produção agropecuária }\end{array}$ & $x$ & $x$ & $x$ & $x$ & $x$ & $x$ \\
\hline $\begin{array}{l}\text { Enfrentamento do } \\
\text { problema da falta de mão } \\
\text { de obra }\end{array}$ & $x$ & & & & $x$ & \\
\hline $\begin{array}{l}\text { Estruturação de cadeias } \\
\text { de valor }\end{array}$ & $\mathrm{x}$ & & $\mathrm{x}$ & $\mathrm{x}$ & $\mathrm{x}$ & $\mathrm{x}$ \\
\hline $\begin{array}{l}\text { Expandir a aplicação do } \\
\text { Plano } A B C\end{array}$ & $x$ & & $\mathrm{x}$ & $\mathrm{x}$ & & \\
\hline $\begin{array}{l}\text { Expansão da geração de } \\
\text { energias renováveis }\end{array}$ & $x$ & $x$ & $\mathrm{x}$ & & $\mathrm{x}$ & $x$ \\
\hline $\begin{array}{l}\text { Expansão da produção } \\
\text { e da produtividade } \\
\text { agropecuária }\end{array}$ & $x$ & $x$ & $x$ & $x$ & $x$ & $x$ \\
\hline $\begin{array}{l}\text { Incentivos à } \\
\text { multifuncionalidade do } \\
\text { espaço rural (turismo, } \\
\text { lazer, etc.) }\end{array}$ & $x$ & $x$ & $x$ & $x$ & $x$ & $x$ \\
\hline $\begin{array}{l}\text { Investimento em } \\
\text { infraestrutura (logística, } \\
\text { energética, comunicaçắo } \\
\text { etc.) }\end{array}$ & $x$ & $x$ & $x$ & $x$ & $x$ & $x$ \\
\hline $\begin{array}{l}\text { Investimentos em } \\
\text { pesquisa e inovação }\end{array}$ & $\mathrm{x}$ & $x$ & $\mathrm{x}$ & $\mathrm{x}$ & $\mathrm{x}$ & $\mathrm{x}$ \\
\hline $\begin{array}{l}\text { Mapear produtos locais } \\
\text { ou regionais }\end{array}$ & & $x$ & $\mathrm{x}$ & & $\mathrm{x}$ & $\mathrm{x}$ \\
\hline $\begin{array}{l}\text { Melhoramento dos } \\
\text { sistemas de informações } \\
\text { (em sentido amplo) }\end{array}$ & $x$ & $x$ & & $x$ & $x$ & $x$ \\
\hline
\end{tabular}


No aspecto econômico, as questões relativas à infraestrutura logística, sanidade, gestão dos riscos (inclusive diante das mudanças climáticas) (GARCIA; BUAINAIN, 2017) e inovação são exemplos de desafios a serem enfrentados pela agropecuária. Em alguns locais no bioma Cerrado, por exemplo, a carente infraestrutura logística reduz em até $30 \%$ os preços agrícolas, além de elevar os preços dos insumos em função dos custos de transporte. Cabe destacar os prejuízos decorrentes de eventos sanitários e climáticos nos quais justamente as populações rurais mais pobres são as que sentem mais duramente os impactos, como bem demonstrou a recente seca no Nordeste.

Importante ressaltar que esses eventos vão além do clima conforme a crise ocorrida recentemente no sistema de certificação de carnes do Brasil. As perdas poderiam ser mitigadas com a implementação de medidas simples enfatizando a gestão integrada de riscos agrícolas ou práticas mais adequadas às condições de cada bioma. Além das perdas devido à infraestrutura logística, a sanidade e a não integração da gestão de riscos, a produtividade da agricultura brasileira, em especial a produtividade da terra, decresceu no período mais recente.

Na questão ambiental um importante desafio ainda é o desmatamento, que apesar dos esforços do governo e da sociedade ainda persiste (IBAMA, 2018; INPE, 2018; MAPBIOMAS, 2018; SOSMA, 2018a). Mas novos desafios emergem com a degradação ambiental e maior demanda por recursos naturais, como o uso da água (ANA, 2017) ou problemas associados ao uso de insumos agroquímicos e contaminação (CARNEIRO et al., 2015), o bem-estar animal, a relação entre agricultura e a própria paisagem. Embora a Produtividade Total dos Fatores Ambientalmente Ajustada (produção agrícola por quantidade emitida de gases do efeito estufa) entre 2004 e 2014 tenha reduzido a taxa de 4,25\% ao ano (ARIAS et al., 2017), a recente alta nos índices de desmatamento deixam uma interrogação sobre este tema. Além da persistência do desmatamento, o aparente agravamento dos ciclos de seca no Nordeste e as recentes crises hídricas verificadas nas regiões Sudeste e Centro Oeste indicam que o uso da irrigação na agricultura, importante vetor para os ganhos de produtividade agrícola, pode estar comprometida.

Embora a agropecuária brasileira tenha registrado um significativo desempenho, os resultados sociais revelam grandes desafios para que o resultado econômico se traduza em melhoria da qualidade de vida na área rural. A pobreza rural ainda não foi superada, apesar dos progressos recentes. Entre 2001 e 2014 a pobreza rural recuou de $48,9 \%$ para $20,2 \%$, mas voltou a crescer nos anos recentes no rastro da crise econômica do país (IPEADATA, 2018). O crescimento da produtividade tem se concentrado em uma pequena proporção dos agricultores brasileiros (ALVES; ROCHA, 2010). Os dados do Censo Agropecuário de 2006 mostram que só 10\% dos agricultores (que possuem renda média e alta) eram responsáveis por $85 \%$ do valor da produção agropecuária, enquanto $90 \%$ dos agricultores (com baixa renda ou situação de extrema pobreza) são responsáveis por apenas $15 \%$ da produção (IBGE, 2006). Os extremamente pobres representam $63 \%$ do total de agricultores, mas contribuíram com menos de 
4\% da produção. A dimensão e os determinantes da pobreza rural no Brasil são bem conhecidas (BUAINAIN; DEDDECA, 2012, 2013) e alguns esforços já possibilitaram sua redução. Apesar dos avanços, ainda falta muito um modelo mais sustentável para a agricultura brasileira, especialmente em termos da inclusão social e da redução dos impactos ambientais.

Em relação aos recursos naturais, base da agricultura, os desafios podem ser alinhados em três eixos:

- $\quad$ Primeiro: é premente a necessidade de recuperar e preservar as características básicas dos biomas, para que possam manter ofluxo de serviços ecossistêmicos indispensáveis, tais como mitigar e reduzir os potenciais impactos das mudanças climáticas sobre a agricultura e sociedade em geral. Na Caatinga, Mata Atlântica e Pampa, por exemplo, o desenvolvimento sustentável implica em recuperar parte do bioma, o que pode exigir severas restrições à expansão da agricultura baseada na ampliação horizontal do uso dos recursos naturais, em particular a terra e água. No caso da Amazônia, Cerrado e Pantanal, a preservação é mais relevante, o que não exclui restrições à expansão da ocupação. Cabe destacar que a recomposição e preservação exigem o aprofundamento do conhecimento de cada bioma e novas ferramentas de gestão ambiental, como a adoção de uma política de Pagamento por Serviços Ambientais (PSAs). Em alguns casos, por exemplo, Mata Atlântica e Caatinga, a estratégia pode vir a ser fomentar o'esvaziamento' agrícola de certos espaços rurais possibilitando assim a recuperação do bioma ou a adoção de práticas fortemente condicionadas à conservação e recuperação ambiental.

- Segundo: promover a utilização eficiente e sustentável dos recursos naturais nos sistemas produtivos agropecuários é tarefa crucial neste processo e, para isso, a inovação tem um papel central. De um lado, o uso eficiente implica, antes de mais nada, reduzir o desperdício dos que já estão operando na (ou próximo da) fronteira tecnológica sustentável, e elevar o rendimento daqueles que ficaram para trás. De outro, a sustentabilidade agropecuária implica reduzir as pressões negativas sobre os ecossistemas, o que implica diminuir o uso de agroquímicos, quando necessário e possível, substituindoos por outros mais inócuos e/ou por práticas alternativas de controle de pragas e doenças; melhorar o uso da água; incorporar um maior número de pequenos e médios agricultores às cadeias de valor mais dinâmicas, dentre outros.

- Terceiro: em função do elevado grau de degradação dos ecossistemas a sociedade tem começado a reconhecer a importância dos serviços ambientais (PARRON \& GARCIA, 2015) e dos serviços ecossistêmicos (MEA, 2003). Neste sentido, se torna necessário promover mudanças mais radicais nos sistemas produtivos, rumo à adoção de abordagens baseadas em 
serviços ecossistêmicos e ambientais, como o Programa ABC, Carne Carbono Zero, ou práticas agroecológicas (ASSIS; ROMEIRO, 2002). No entanto, esse movimento, importantíssimo, não tem sido suficiente. É preciso ir além dos sistemas produtivos "verdes" que, com certo apoio, podem ser viabilizados pelos mercados. É preciso incorporar um conjunto de práticas de alto valor para a sociedade, mas que ainda não são adequadamente remuneradas, por exemplo, os serviços ambientais vinculados à produção orgânica, agroecológica e mesmo às diversas práticas de manejo mais conservacionistas. Para isso, a sociedade deve reconhecer o papel dos programas de PSAs na recuperação e manutenção da qualidade ambiental, o que inclui desde a valorização da água captada em seus mananciais até "produção" de água e controle da erosão pelos produtores rurais. É preciso ter claro que a recuperação, proteção e uso sustentável e inclusivo dos recursos naturais nos biomas brasileiros exige mais que inovação tecnológica. É necessário, de um lado, gerar conhecimento; de outro, adotar inovações organizacionais e institucionais para criar incentivos e viabilizar a implementação de programas, políticas e iniciativas nas linhas da estratégia de promover a transição para uma agricultura sustentável. O aumento dos custos de produção, em função da perda da qualidade ambiental do solo e água, por exemplo, estão se tornando uma limitação para os produtores. Essa estratégia baseada no incremento tecnológico para compensar a perda de qualidade ambiental tem mostrado sinais de esgotamento.

Outra questão para aprofundar a trajetória rumo à uma agricultura mais sustentável e em conformidade com as tendências que emergem nos mercados mundiais, e mesmo no Brasil, implica em dois aspectos cruciais para construir novas capacidades, que possam sustentar esta repactuação em prol da qualidade ambiental. Por um lado, é preciso criar aquilo que vem sendo denominado por 'inteligência territorial ou regional'. Aqui a questão central não é somente aumentar a geração e a organização de dados sobre os territórios (biomas) nos quais se executa a atividade agropecuária, mas sim gerar mais e melhores análises para identificar oportunidades e a constituição de melhores e mais eficientes processos de tomada de decisão e formas de monitoramento e uso dos recursos locais.

Se o ciclo anterior de desenvolvimento se sustentou na ideia de que seria possível e desejável uniformizar ou industrializar os métodos de produção, por meio da padronização de tecnologias e insumos, o que se vê agora é o contrário. É premente adotar instrumentos de apoio ao monitoramento e planejamento enfatizando não apenas o zoneamento dos recursos naturais. A agricultura carece de um zoneamento ecológico-econômico. O território brasileiro é extremamente diversificado, e os traços comuns que o caracterizam não são suficientes para esconder a diversidade de microclimas, topografias, culturas e tradições. 
Isto significa um enorme potencial a ser explorado, que não se contrapõe, necessariamente, à produção sustentável em larga escala, que pode se beneficiar da presença de sistemas produtivos diversificados e da provisão dos serviços ecossistêmicos. Ao mesmo tempo, é preciso pensar em formas de planejamento estratégico no uso de recursos, rediscutindo vocações territoriais e regionais e identificando oportunidades de geração de renda e de emprego onde não será possível ou desejável expandir a produção em função dos custos ambientais, sociais e econômicos. Não há dúvidas, portanto, quanto à necessidade de aprimorar o conhecimento e monitoramento dos diferentes espaços geográficos do país, definidos por aspectos econômicos, sociais e ambientais. A questão que se coloca é: qual o recorte espacial mais adequado para se promover a inteligência regional do setor agrícola brasileiro?

Outro importante desafio é a questão da infraestrutura. Desnecessário se estender sobre o déficit - na verdade, déficits - de infraestrutura que reduzem a competitividade da agricultura brasileira e sua eficiência, os quais estão na base de distorções alocativas e distributivas que têm reforçado o processo de concentração da produção associado a vantagens de escala. Esse contexto contribui para ampliar a degradação ambiental, em função da perda de produção e de recursos naturais. O fato é que, devido ao déficit de infraestrutura, em muitos territórios apenas os grandes produtores, produzindo em larga escala, são viáveis. Enfrentar esse déficit é fundamental para o desenvolvimento rural e para explorar adequadamente o enorme potencial dos biomas, o que vai bem além da produção de commodities e da própria produção agropecuária. A aproximação dos meios urbano e rural pode abrir muitas oportunidades de desenvolvimento rural e de melhoria de bem-estar em geral, inclusive ambiental, explorando as novas tendências de circuitos curtos, 'gourmetização' da alimentação, produtos locais, turismo e lazer, acesso a mercados para agricultores familiares, acesso a bens e serviços públicos muitas vezes disponíveis somente em centros urbanos, entre outros aspectos.

Parte dessa transição envolve infraestrutura e agricultura apoiada naquilo que está sendo denominado sistemas produtivos 4.0. Em praticamente todos os biomas ficou claro que a agricultura 4.0, hoje ainda embrionária, será a realidade dominante, com múltiplas funções e papéis desde o uso mais racional de agroquímicos e água, combate às pragas, controle de qualidade. A infraestrutura requerida por essa 'nova' agricultura vai muito além da logística (armazenamento e transportes), a qual deve ser renovada no sentido da agregação de valor à produção agrícola. A agricultura 4.0 também carece de comunicação e demais infraestruturas para atendimento de necessidades básicas da sociedade, como saneamento, energia, água e comunicação. A depender da forma como se organizam, ações voltadas ao equacionamento destes desafios poderiam contribuir para a redução da desigualdade e, consequentemente, fortalecimento da democracia. 
No entanto, ao mesmo tempo em que pode contribuir para uma agricultura mais sustentável, a agricultura 4.0 tem potencial de amplificar os problemas sociais, como a concentração da renda e da riqueza gerando, portanto, maior exclusão. A agricultura 4.0 pode ser utilizada por pequenos agricultores, mesmo nas condições da heterogeneidade que caracteriza o Brasil, o que poderia amenizar ou mesmo reverter o quadro de profunda desigualdade. De um lado, o pacote é intensivo em capital e conhecimento, e a realidade da maioria dos agricultores familiares e pequenos é de falta de capital e de conhecimento apropriado para o uso deste tipo de tecnologia; de outro, é também intensiva em gestão, e em gestão sofisticada, que integra múltiplas dimensões do processo de produção. É também neste aspecto que os pequenos agricultores, enredados em práticas mais tradicionais, ou absorvidos pela pobreza própria ou que os circunda, têm déficits e precisariam de apoio para superá-los. Termos como agricultura 4.0, agricultura de precisão e outros, apontam para a necessidade de maior adaptação local e social das tecnologias utilizadas.

Esse processo exige pensar a organização dos mercados, não simplesmente sob a ótica da organização e articulação das cadeias, mas incluindo a perspectiva dos mercados regionais que não deve se limitar à agregação de valor à produção agrícola. Implica incluir o fornecimento de máquinas, insumos etc., além do mercado de serviços (técnicos, financeiros etc.), bem como o desenvolvimento de 'novos' mercados baseados em produtos típicos do bioma, novos produtos da biodiversidade, agroecologia e produção orgânica e agroturismo, entre outros.

Como mencionado, a inovação e a transição para uma'nova'agricultura demandam pesquisa, monitoramento, geração e análise de informações a partir de perguntas e de novas expertises. O eixo de inovação deve focar o aumento da produtividade econômica por meio do aumento na produtividade física, agregação de valor, diversificação da produção e reduções do desperdício e do custo, porém, não pode perder de vista a sustentabilidade ambiental e social da produção no espaço rural. Isso implica em uma intensificação produtiva, mas que considere alternativas sustentáveis, incorporando os cenários climáticos (mitigação e adaptação às mudanças climáticas), a inclusão produtiva, tais como a geração de emprego, renda e de soluções para produtores marginalizados, a inovação para a agricultura 4.0, a inovação para gestão produtiva e a inovação para a criação de novos mercados.

A inovação depende do empreendedorismo do produtor rural, o qual tem forte relação com o fortalecimento da assistência técnica e extensão rural. Em um novo modelo que considere as novas ferramentas e ações de produção e transferência de informação como forma de permitir acesso a tecnologias desenvolvidas e adaptadas. Desenvolver sistemas de informação de fácil acesso, fortalecer e reestruturar as ATER's e qualificar os profissionais envolvidos não é tarefa trivial e requer estudos enfatizando as novas ferramentas de inovação vis a vis os novos mercados que surgirão com a agricultura 4.0. 
O outro tema crucial, relevante em todos os biomas, é o da construção de instituições no sentido do conjunto de regras e marcos para o funcionamento do setor, como a indicação geográfica e sanidade, além de incentivos para a preservação e sustentabilidade socioeconômica ambiental. Isso requer o aprimoramento do aparato legal e institucional em direção à transição para uma agricultura sustentável incorporando a ideia de um ambiente institucional capaz de dialogar com todos os setores envolvidos, além da formação de capacidades institucionais para a nova visão que exige a coordenação tripla Estado/sociedade/mercado, intergovernamental e intersetorial.

Com diferentes ênfases, a necessidade de aperfeiçoamento das políticas apareceu como prioridade entre os participantes das oficinas realizadas. As políticas públicas (crédito, gestão de risco, sanidade etc.) devem acompanhar a transição para uma agricultura sustentável (agroecologia, produção orgânica, Programa $A B C$, mudanças climáticas, combate ao desmatamento, inclusão social etc.). Portanto, devem ser implementados instrumentos de avaliação com ênfase em reduzir a falta de coordenação e que incentivem a integração dessas políticas. Tendo como foco melhorar o grau de eficiência, alcance e efetividade, em especial, no caso dos agricultores familiares e pequenos de baixa renda. No modelo de agricultura sustentável não será possível mais conviver com políticas públicas fragmentadas e falta de articulação que incentivem o gap rural-urbano e demais desigualdades sociais, muito menos que negligenciem os direitos de comunidades menos favorecidas como as tradicionais e a agricultura familiar.

Para tanto, a capacitação e qualificação dos recursos humanos se faz urgente, assim como, a promoção da educação e da saúde no espaço rural. Ou seja, é premente o desenvolvimento de novas regras de interação entre os agentes, tanto no sentido de quem são os agentes desta transição, como no sentido dos parâmetros que precisarão ser adotados para regular as relações entre Estado, sociedade e natureza. A dicotomia que hoje marca grande parte dos debates opondo competitividade à conservação, o grande agronegócio e a agricultura familiar, terão que dar espaço, sem negar as diferenças existentes, à busca de convergências orientadas pelos propósitos aqui mencionados. Sem isso, parte dos atores e das habilidades fundamentais a uma agenda de transição para a agricultura e o mundo rural do século XXI não serão mobilizados, e o grau de sucesso estará fortemente comprometido.

\section{CONSIDERAÇÕES FINAIS}

Percebe-se, em rápida análise dos desafios, que a maioria deles se manifesta em vários biomas, naturalmente com intensidade diferenciada. Na dimensão ambiental, como indicado acima, os desafios poderiam ser resumidos em uma tríade: recuperação, preservação e utilização sustentável da riqueza ambiental do país. Destacam-se os seguintes: 
1. recuperação das áreas degradadas, em sentido amplo;

2. desenvolver mecanismos para viabilizar o pagamento por serviços ambientais;

3. preservação e aproveitamento da biodiversidade;

4. preservação ambiental, latu senso;

5. gestão hídrica.

Ainda nesta dimensão se destacam alguns desafios que poderiam ser agrupados como de natureza mais institucional, como é o caso da criação de unidades de conservação, implementação de programas de educação ambiental, regularização fundiária e ambiental e o fortalecimento da capacidade de monitoramento, fiscalização e aplicação da institucionalidade ambiental, incluindo tanto as funções de polícia ambiental como a Justiça e as instâncias administrativas. É evidente que a dimensão ambiental, oferece um campo amplo para sua atuação no Brasil. A mais evidente necessidade, que poderia beneficiar o conjunto dos biomas e das ações, é justamente o apoio ao fortalecimento da capacidade de gestão ambiental do Estado brasileiro, que inclui monitoramento remoto, fiscalização, recursos humanos, tecnologia e regulação. O desenvolvimento de inteligência regional, com visão sistêmica e integrada, é sem dúvida uma prioridade para o país.

Na dimensão social, tomando como base a agricultura, o maior desafio é promover a inclusão produtiva e social da agricultura familiar, em particular dos grupos mais pobres que têm sido marginalizados dos progressos da agropecuária nas últimas décadas, e garantir os direitos constitucionais de grupos étnicos e comunidades tradicionais. Em uma abordagem mais abrangente de desenvolvimento rural, o desafio é enfrentar a pobreza rural e as desigualdades, em todas as suas dimensões. Isto implica ajustes no próprio modelo de desenvolvimento que tem caracterizado a dinâmica econômica do país, e também da agricultura, e um rol de políticas públicas, da educação à saúde, passando pelos sistemas de proteção social, e reformas cuja análise está além dos objetivos deste exercício.

Em termos mais específicos, destacam-se os seguintes desafios:

1. Reformular o modelo de assistência técnica e extensão rural e fortalecer a capacidade do Estado prover estes serviços, cuja ausência foi apontada como um dos principais responsáveis pelo atraso tecnológico de parte dos pequenos produtores de base familiar;

2. Fortalecer as organizações dos produtores, como as cooperativas e associações comunitárias e ou de pequenos produtores, indispensável para superar as restrições de escala que enfrentam para a adoção de sistemas produtivos mais produtivos e sustentáveis e para acessarem mercados em geral; 
3. Aproximar a pesquisa das necessidades e possibilidades de aplicação destes segmentos marginalizados, com ênfase para tecnologias compatíveis com especificidades locais e destes grupos sociais;

4. Aprimorar os incentivos e demais instrumentos como crédito e formas de inserção em mercados apoiando-se nos aprendizados gerados com a criação atual de políticas e programas.

As opções para a inclusão dos pequenos produtores mais pobres, muitas vezes não estão na produção de commodities, onde a escala é preponderante. No entanto, as tendências dos mercados de produtos agropecuários explicitadas acima, que demandam mais "conteúdo local", com origem conhecida, resultado de práticas sustentáveis, abre um leque de oportunidades para os pequenos produtores. Não há mais que assumir que este segmento tem vantagens associadas à disponibilidade de mão de obra familiar - que é crescentemente escassa - ou à aplicação de conhecimentos tradicionais, que nem sempre se coadunam à realidade e demanda dos mercados. Trata-se de assumir que, mesmo em desvantagem devido aos déficits de toda natureza acumulados e que se traduzem, em última análise, na pobreza, é preciso apoiar a capacitação dos pequenos produtores e a criação de ambientes institucionais mais favoráveis ao aproveitamento destas oportunidades. Neste sentido, o apoio a estratégias de diversificação produtiva, educação e capacitação técnica, valorização 
dos jovens e criação de oportunidades para melhores vínculos entre os espaços urbanos e rurais, produção e difusão de novas tecnologias, não apenas por meio de assistência técnica e extensão rural, mas também provendo os meios financeiros adequados para sua adoção, são alguns dos desafios e recomendações propostas pelas partes interessadas.

As oportunidades neste campo são inúmeras. No plano federal, a mais óbvia é a reformulação do modelo de assistência técnica e extensão rural, indispensável principalmente quando se leva em conta que a maioria dos estados não tem - e nem terá no médio prazo - capacidade para atuar de forma consistente nesta área. No plano das ações junto aos estados, na área rural, a opção estratégica deveria ser a de apoiar projetos de promoção de inclusão produtiva com base na'nova' agricultura, indo além das visões e desenhos de projetos de combate à pobreza rural que têm caracterizado a atuação dos organismos internacionais no Brasil.

Na dimensão econômica os principais desafios são promover o crescimento da produção sustentável, a elevação da produtividade, a diversificação dos sistemas produtivos em todos os biomas e a transição para padrões da 'nova' agricultura, que incorpore a institucionalidade da sustentabilidade e atenda à crescente demanda por produtos limpos, saudáveis e socialmente éticos, tendo como base o melhor aproveitamento das potencialidades particulares de cada bioma. Nesta direção, os principais desafios podem ser agrupados segundo a natureza:

1. Investimentos em pesquisa, notadamente aquelas voltadas aos ganhos de produtividade ambientalmente ajustada e a agricultura 4.0, ou outras práticas produtivas adaptadas às características socioambientais. No caso da agricultura 4.0, o Brasil já conta com mais de uma centena de AgTech (startups dedicadas ao setor agrícola), inclusive para pequena produção e agricultura familiar. As possibilidades nesse caso iniciam pela simples catalogação e organização desse ecossistema e se estende até o apoio às AgTech já estabelecidas, passando pelo apoio a incubação de startups junto aos centros de pesquisa; no caso das demais práticas produtivas, o desafio consiste em ir além das chamadas práticas alternativas e conferir maior robustez a um arquipélago de iniciativas potenciais que vem sendo praticadas por produtores mais pobres ou por segmentos destacados da agricultura familiar em cada bioma.

2. infraestrutura (logística, energética e comunicação) aparece como prioridade para todos os biomas;

3. incentivar o turismo rural e ambiental e a adoção de sistemas integrados de produção (orgânica, agroecológica, agroflorestal etc.);

4. reforçar a capacidade de planejamento para o desenvolvimento rural e da agricultura, incluindo o aperfeiçoamento do instrumento de Zoneamento Econômico-Ecológico, os planos safras, os planos de gestão das bacias 
hidrográficas, a inteligência territorial, os sistemas de informações gerais para os produtores, dentre outros;

5. modernizar e reforçar o sistema de defesa sanitária animal e vegetal;

6. reforçar os instrumentos de financiamento público, com ênfase no acesso dos pequenos produtores a linhas de crédito adequadas para viabilizar os investimentos em sistemas produtivos sustentáveis;

7. incentivar a implementação de um sistema integrado de gestão do risco agrícola calcado não só na transferência do risco (seguro), mas, principalmente na sua mitigação e na difusão da informação;

8. apoiar, onde for viável e sustentável, a adoção da irrigação e a 'produção de água', levando em conta o uso racional e sustentável dos recursos hídricos;

9. promover sistemas dedicados à difusão das inovações e tecnologias, em particular voltadas para os pequenos produtores, apropriadas para a escala na qual operam e para superar a crescente escassez da mão de obra familiar;

10. incentivar a extensão rural, assistência técnica e capacitação de mão de obra atendendo as especificidades de cada bioma.

As contribuições colhidas foram relevantes, porém, talvezo desafio mais importante seja a ausência de um pensamento estratégico envolvendo as interdependências entre as dimensões econômico-produtiva, social, ambiental e institucional, ou mesmo sobre algumas das dimensões em si, ainda que isoladamente. Assim, é urgente apoiar formas e processos que contribuam para a formulação de uma agenda estratégica de: (i) longo prazo sobre agricultura sustentável e desenvolvimento rural no Brasil; (ii) de médio prazo, tratando da transição do sistema atual para a agricultura do século XXI. Esta agenda não será obra exclusiva de intelectuais ou órgãos de governo, nem tampouco de empresas ou lideranças do setor, isoladamente. Ela precisa resultar de um pacto entre as principais forças sociais da agricultura, do meio rural, e mesmo de setores mais amplos da sociedade brasileira. O Brasil já produziu grandes transições assim ao longo de sua História. Os tempos atuais exigem que se volte a pensar em transformações estruturais, de longo prazo, e que sejam a base de novos contratos entre Estado, sociedade e agentes de mercado.

\footnotetext{
Notas

'Bioma é "um conjunto de vida (vegetal e animal) constituído pelo agrupamento de tipos de vegetação contíguos e identificáveis em escala regional, com condições geoclimáticas similares e história compartilhada de mudanças, o que resulta em uma diversidade biológica própria" (IBGE, 2004).

${ }^{2}$ Os resultados foram registrados em template próprio, preparado pela equipe de consultores, contendo as potencialidades, desafios e ações necessárias à implementação da agricultura sustentável no bioma em questão.
} 


\section{Referências}

ALVES, E.; ROCHA, D. DE P. Ganhar tempo é possível? In: GASQUES, J. G.; VIEIRA FILHO, J. E.; NAVARRO, Z. (Eds.). A agricultura brasileira: desempenho, desafios e perspectivas. $1^{\text {a }}$ ed. BrasíliaDF: Instituto de Pesquisa Econômica e Aplicada - Ipea, 2010. pp. 275-290.

ALVES, E.; SOUZA, G. DA S. E; ROCHA, D. DE P. Lucratividade da agricultura. Revista de Política Agrícola, v. 21, n. 2, pp. 45-63, 2012.

ANA. Mudanças Climáticas e Recursos Hídricos: avaliações e diretrizes para adaptação. Brasília-DF: Disponível em: https://bit.ly/330ZUxa. Acesso em: 27 Mai. 2018.

ANA. Atlas Irrigação: Uso da Água na Agricultura Irrigada. Brasília-DF: [s.n.]. Disponível em: https://bit.ly/2Z2I1S1. Acesso em: 12 nov. 2018.

ANA. Divisão Hidrográfica - Sistema Nacional de Informações sobre Recursos Hídricos. Disponível em: https://bit.ly/2Mtjiyk. Acesso em: 12 nov. 2018.

ARIAS, D. et al. Agriculture Productivity Growth in Brazil: Recent trends and future prospects. Washington, DC.: [s.n.]. Disponível em: https://bit.ly/2P3p6Rm. Acesso em: 12 nov. 2018.

ASSIS, R. L.; ROMEIRO, A. R. Agroecologia e agricultura orgânica: controvérsias e tendências. Desenvolvimento e Meio Ambiente, n. 6, pp. 67-80, 2002.

ATLAS BRASIL. Atlas do Desenvolvimento Humano no Brasil. Disponível em: <http://atlasbrasil. org.br/2013/>. Acesso em: 3 mar. 2018.

BRASIL. Plano Nacional De Agroecologia E Produção Orgânica - Planapo. Ministério do Desenvolvimento Agrário Brasília, p. 92, 2013.

BUAINAIN, A. M.; DEDDECA, C. S. A nova cara da pobreza rural: desafios para as políticas públicas. $1^{\text {a }}$ ed. Brasília-DF: IICA - Instituto Interamericano de Cooperação para a Agricultura, 2012.

BUAINAIN, A. M.; GARCIA, J. R. Polos de irrigação no Nordeste do Brasil. Revista Franco-Brasileira de Geografia, 2015.

CARNEIRO, F. F. et al. (Org.). Dossiê ABRASCO: um alerta sobre os impactos dos agrotóxicos na saúde. [s.l: s.n.].

CASIMIRO FILHO, F.; IVONEIDE, M.; RODRIGUES, V. Convivência com a escassez de água : a importância do capital social nas áreas susceptíveis à desertificação no Semiárido. Sustentabilidade em Debate, n. 7, pp. 114-135, 2016.

CEPEA. Centro de Estudos Avançados em Economia Aplicada - CEPEA-Esalq/USP. Disponível em: <https://www.cepea.esalq.usp.br/br>. Acesso em: 28 nov. 2017.

FAOSTAT. Food and agriculture data. Disponível em: <http://www.fao.org/faostat/en/\#home>. Acesso em: 25 ago. 2017.

FIRJAN. IFDM | Índice FIRJAN de Desenvolvimento Municipal: Consulta. Disponível em: <https:// www.firjan.com.br/ifdm/>. Acesso em: 12 dez. 2018.

GARCIA, J. R. Trabalho rural: Tendências em face das transformações em curso. In: BUAINAIN, A. M. et al. (Eds.). O mundo rural no Brasil do século 21: a formação de um novo padrão agrário e agrícola. $1^{\text {a }}$ ed. Brasília-DF: Empresa Brasileira de Pesquisa Agropecuária - Embrapa, 2014. pp. 559-590.

GARCIA, J. R.; BUAINAIN, A. M. Os desafios do risco ambiental no século XXI para o setor de seguro. Espacios, v. 38, n. 31, p. 11, 2017. 
GASQUES, J. G.; BACCHI, M. R. P.; BASTOS, E. T. Crescimento e Produtividade da Agricultura Brasileira de 1975 a 2016. Ipea, Carta de Conjuntura. n. 38, p. 9, 2018.

IBAMA. PMDBBS - Projeto de Monitoramento do Desmatamento dos Biomas Brasileiros por Satélite. Disponível em: <http://siscom.ibama.gov.br/monitora_biomas/index.htm>. Acesso em: 1 jun. 2018.

IBGE. Mapa de Biomas e de Vegetação. Disponível em: < https://bit.ly/2BAXYRs>. Acesso em: 12 dez. 2018.

IBGE. Sistema IBGE de Recuperação Automática - SIDRA. Disponível em: <https://sidra.ibge.gov. br/home/scnt/brasil>. Acesso em: 3 mar. 2018a.

IBGE. Biomas continentais do Brasil. Brasília-DFInstituto Brasileiro de Geografia e Estatística IBGE, 2018b. Disponível em: https://bit.ly/2NjKz6b. Acesso em: 12. nov. 2018.

IBGE. IBGE | mapas. Disponível em: <http://mapas.ibge.gov.br/>. Acesso em: 3 mar. 2018c.

IBGE - INSTITUTO BRASILEIRO DE GEOGRAFIA E ESTATÍSTICA. Mapa de Biomas e de Vegetação. Disponível em: <https://ww2.ibge.gov.br/home/presidencia/noticias/21052004biomashtml. shtm>. Acesso em: 5 set. 2017.

IBGE, I. B. Censo Agropecuário 2006, 2006. Disponível em: https://bit.ly/2Hgnn4W. Acesso em: 17 jun. 2018.

INPE. PRODES - Projeto de Monitoramento do Desmatamento na Amazônia Legal por Satélite. Disponível em: <http://www.obt.inpe.br/prodes/dashboard/prodes-rates.html>. Acesso em: 14 mar. 2018.

IPEADATA. Base de dados socioeconômicos do Instituto de Pesquisa Econômica e Aplicada. Disponível em: <http://www.ipeadata.gov.br/>. Acesso em: 23 maio. 2018.

MAPA. Plano ABC - Agricultura de Baixa Emissão de Carbono - Ministério da Agricultura, Pecuária e Abastecimento. Disponível em: https://bit.ly/2YZEuTk. Acesso em: 14 mar. 2018a.

MAPA. Estatísticas de Comércio Exterior. Disponível em: https://bit.ly/2ZglzBU. Acesso em: 24 mar. 2018.

MAPBIOMAS. Mudanças de cobertura e uso: Mapbiomas v. 3.0. Mapbiomas, 2018. Disponível em: <http://mapbiomas.org/map\#transitions>. Acesso em: 24 mar. 2018.

MEA. Ecosystems and Human Well-being: A framework for Assessment. In: MA Conceptual framework. [s.l: s.n.]. p. 1-25.

MMA - MINISTÉRIO DO MEIO AMBIENTE. Download de dados geográficos. Disponível em: <http://mapas.mma.gov.br/i3geo/datadownload.htm>. Acesso em: 25 fev. 2018.

OCDC-FAO. Perspectivas agrícolas. Agricultural Outlook 2017-2026, pp. 1-4, 2017.

PALM, C. et al. Conservation agriculture and ecosystem services: An overview. Agriculture, Ecosystems and Environment, v. 187, 2014.

PARRON, L. M.; GARCIA, J. R. Serviços ambientais: conceitos, classificação, indicadores e aspectos correlatos. Serviços Ambientais em Sistemas Agrícolas e Florestais do Bioma Mata Atlântica, 2015.

PÉRA, T. G. Perdas na logística de granéis sólidos agrícolas no Brasil. Piracicaba: Esalq/USP, , 2018. Disponível em: https://bit.ly/2Zanuol. Acesso em: 24 mar. 2018.

ROMEIRO, A. R. O agronegócio será ecológico. In: BUAINAIN, A. M. et al. (Eds.). O mundo rural no Brasil do século XXI: a formação de um novo padrão agrário e agrícola. $1^{\mathrm{a}}$ ed. Brasília-DF: Embrapa, 2014. 
SFB. SNIF - Os Biomas e Suas Florestas. Disponível em: <http://snif.florestal.gov.br/pt-br/osbiomas-e-suas-florestas>. Acesso em: 12 nov. 2018.

SOSMA. Atlas da Mata Atlântica. Disponível em: https://bit.ly/2UHSwWZ. Acesso em: 25 fev. 2018.

SOSMA. Florestas: A Mata Atlântica. Disponível em: https://bit.ly/1J2VffR. Acesso em: 25 fev. 2018.

UN COMTRADE. International Trade Statistics Database. Disponível em: <https://comtrade. un.org/>. Acesso em: 12 dez. 2018.

USDA. International Agricultural Productivity. Disponível em: https://bit.ly/31S22GY. Acesso em: 16 mar. 2018.

ZHANG, W. et al. Ecosystem services and dis-services to agriculture. Ecological Economics, v. 64, n. 2, pp. 253-260, 2007. 